\title{
Strength development of cement-treated sand using different cement types cured at different temperatures
}

\author{
Lanh Si Ho ${ }^{1,2}$, Kenichiro Nakarai ${ }^{2,}{ }^{,}$, Kenta Eguchi $^{2}$, Takashi Sasaki ${ }^{3}$, and Minoru Morioka ${ }^{3}$ \\ ${ }^{1}$ Geotechnical Engineering and Artificial Intelligence research group (GEOAI), University of \\ Transport Technology, 54 Trieu Khuc, Thanh Xuan, Hanoi, Vietnam \\ ${ }^{2}$ Hiroshima University, Department of Civil and Environmental Engineering, Graduate School of \\ Engineering, 1-4-1, Kagamiyama, Higashi-Hiroshima, Hiroshima 739-527, Japan \\ ${ }^{3}$ Denka Co., Ltd., Cement \& Special Cement Additives Research Dept., Omi Plant, 2209 Oaza Omi, \\ Itoigawa, Niigata 949-0393, Japan
}

\begin{abstract}
This study aimed to investigate the strength development of cement-treated sand using different cement types: ordinary Portland cement (OPC), high early strength Portland cement (HPC), and moderate heat Portland cement (MPC) cured at different temperatures. The cementtreated sand specimens were prepared with $8 \%$ of cement content and cured under sealed conditions at $20^{\circ} \mathrm{C}$ and $40^{\circ} \mathrm{C}$, and mortar specimens were also prepared for reference. The results showed that the compressive strength of cement-treated sand increased in order of MPC, OPC, and HPC under high curing temperatures. It was interesting that the compressive strength of the specimens using HPC was much larger than that of the specimen using $\mathrm{OPC}$ and $\mathrm{MPC}$ under $20^{\circ} \mathrm{C}$ due to the larger amount of chemically bound water. Additionally, it was revealed that under high curing temperatures, the pozzolanic reaction was accelerated in the cement-treated sand; this may be caused by the high proportions of sand in the mixtures.

Keywords: Cement-Treated Sand, Compressive Strength, Cement Types, Curing Temperatures, Cement Hydration, Pozzolanic Reaction.
\end{abstract}

\section{Introduction}

Cement-treated soils have been applied popularly for soft soil improvement, especially for the deep mixing method. It is known that the compressive strength of cement-treated soils is considered an important indicator to characterize soil behavior [1-3]. The strength development of cement-treated soils is governed by many factors such as conditions of soil, mixing, and curing [4]. In terms of curing conditions, the curing temperature is an important factor that affects the strength development of cement-treated sand. With regards to the deep mixing method, large columns of cement-treated soils are usually used. A previous study on the temperature history of field deep mixing columns revealed that the

\footnotetext{
* Corresponding author: nakarai@hiroshima-u.ac.jp
} 
temperature in the core of column produced from cement hydration reached approximately $50^{\circ} \mathrm{C}$ and maintained that temperature for several months [5]. It implies that the core of the deep mixing column was subjected to high temperatures. This high temperature may also promote the hydration and pozzolanic reaction process.

In the field of concrete engineering, the strength at an early age was accelerated by high curing temperatures because the cement hydration process is promoted under that condition [6-8]. However, it was stated that the long-term strength of concrete decreased under high curing temperatures because main hydrated cement products formed have no time to arrange suitably, and this causes a loss of strength. This behavior had been called as the crossover effect [9-11]. On the other hand, some previous studies on cement-stabilized clay found that the strength development in both short and long-term increased under high curing temperatures due to the acceleration of cement hydration and pozzolanic reactions $[12,13]$.

Up to date, very few studies have quantitatively evaluated the effect of curing temperatures and the relationship between the curing temperature and strength in terms of chemical reactions on the strength development of cement-treated soils. It is known that ordinary Portland cement is often used for cement-treated soils, but there are few studies on cases where different types of cement are used, such as high early strength and moderate heat Portland cements. The effects of the curing temperature and cement type on the strength development mechanism of cement-treated soils have not been investigated longterm. Thus, this study aims to investigate the strength development mechanism of cementtreated sand using three types of cement cured under different temperatures $\left(20^{\circ} \mathrm{C}\right.$ and $40^{\circ} \mathrm{C}$ ) through chemical tests.

\section{Materials and measurements}

\subsection{Materials and specimens}

\subsubsection{Mix proportions, mixing, and compaction}

Toyoura silica sand was used as the natural standard sand for experiments in Japan that has low pozzolanic reactivity ( $166 \mathrm{mg}$ of $\mathrm{CaO}$ consumed by $1 \mathrm{~g}$ of sand determined by the French standard for the modified Chapelle test NF P18-513). Three types of cement were used including ordinary Portland cement (OPC), moderate heat Portland cement (MPC), and high early strength Portland cement (HPC). The chemical compositions of the sand and cement are shown in Table 1.

In the case of cement-treated sand, both the designed cement and water contents were $8 \%$ by the weight of the dried sand. Table 2 shows the mix proportions of the cementtreated sand, where water/cement (W/C) was chosen to be $100 \%$. Details of the mixing procedure can be found in previous studies [14,15]. After mixing, cylindrical specimens 50 $\mathrm{mm}$ in diameter and $100 \mathrm{~mm}$ in height were cast by compaction using a rammer with a weight of $1.5 \mathrm{~kg}$ based on the JCAS L-01:2006 standard.

Two types of mortar with normal and high water/cement ratios $(\mathrm{W} / \mathrm{C}=50$ and $\mathrm{W} / \mathrm{C}=$ $100 \%)$ were used. The mortar with a high water/cement ratio $(\mathrm{W} / \mathrm{C}=100 \%)$ was prepared to produce a mixture having the same water/cement ratio as the cement-treated sand for comparison. The mix proportion of the mortar is shown in Table 3. The fresh mortar was mixed using a mixer. For the case of the mortar with $\mathrm{W} / \mathrm{C}=100 \%$, because it contained a high quantity of water, the mortar after mixing was immediately put in a sealed plastic bag and kneaded. The mortar specimens with $50 \mathrm{~mm}$ in diameter and $100 \mathrm{~mm}$ in height were cast by hand tapping. 
Table 1. Chemical composition of cement and Toyoura silica sand (\%).

\begin{tabular}{|c|c|c|c|c|}
\hline \multirow{2}{*}{ Chemical composition $(\%)$} & \multicolumn{4}{|c|}{ Material } \\
\hline & Toyoura silica sand & OPC & HPC & MPC \\
\hline LOI & 0.37 & 2.48 & 1.38 & 0.83 \\
\hline Insoluble residue & - & 0.17 & 0.14 & 0.15 \\
\hline $\mathrm{SiO}_{2}$ & 92.54 & 20.16 & 20.15 & 23.66 \\
\hline $\mathrm{Al}_{2} \mathrm{O}_{3}$ & 2.96 & 5.22 & 4.98 & 3.62 \\
\hline $\mathrm{Fe}_{2} \mathrm{O}_{3}$ & 0.35 & 2.84 & 2.85 & 4.41 \\
\hline $\mathrm{CaO}$ & 0.19 & 64.69 & 65.22 & 63.21 \\
\hline $\mathrm{MgO}$ & 0.05 & 0.96 & 0.94 & 0.71 \\
\hline $\mathrm{SO}_{3}$ & 0.02 & 2.14 & 3.06 & 2.02 \\
\hline $\mathrm{Na}_{2} \mathrm{O}$ & 0.58 & 0.23 & 0.23 & 0.26 \\
\hline $\mathrm{K}_{2} \mathrm{O}$ & 2.75 & 0.39 & 0.39 & 0.35 \\
\hline $\mathrm{TiO}_{2}$ & 0.1 & - & - & - \\
\hline $\mathrm{MnO}$ & $<0.01$ & - & - & - \\
\hline $\mathrm{P}_{2} \mathrm{O}_{5}$ & 0.02 & - & - & - \\
\hline $\mathrm{BaO}$ & 0.05 & - & - & - \\
\hline
\end{tabular}

Table 2. Mix proportion of cement-treated sand.

Table 3. Mix proportion of mortar.

\begin{tabular}{|c|c|c|c|}
\hline $\begin{array}{c}\text { Name of } \\
\text { mixture }\end{array}$ & $\begin{array}{c}\text { Cement } \\
\text { type }\end{array}$ & $\begin{array}{c}\text { Cement } \\
\text { /dried } \\
\text { sand } \\
\text { (\%) }\end{array}$ & $\begin{array}{c}\text { Water/ } \\
\text { dried } \\
\text { sand } \\
\text { (\%) }\end{array}$ \\
\hline S-8(O) & OPC & \multirow{2}{*}{8} & \multirow{2}{*}{8} \\
\cline { 1 - 2 } S-8(H) & HPC & & \\
\cline { 1 - 2 } S-8(M) & MPC & & \\
\hline
\end{tabular}

\begin{tabular}{|c|c|c|c|}
\hline $\begin{array}{l}\text { Name of } \\
\text { mixture }\end{array}$ & $\begin{array}{c}\text { Cement } \\
\text { type }\end{array}$ & $\begin{array}{c}\text { W/ } \\
\mathbf{C} \\
(\%)\end{array}$ & $\begin{array}{c}\text { Cement/ dried } \\
\text { sand }(\%)\end{array}$ \\
\hline M50(O) & OPC & \multirow{3}{*}{50} & \multirow{3}{*}{50} \\
\hline M50(H) & HPC & & \\
\hline M50(M) & MPC & & \\
\hline $\mathrm{M} 100(\mathrm{O})$ & OPC & \multirow{3}{*}{100} & \multirow{3}{*}{25} \\
\hline $\mathrm{M} 100(\mathrm{H})$ & HPC & & \\
\hline M100(M) & MPC & & \\
\hline
\end{tabular}

\subsubsection{Curing conditions}

In this study, the specimens of cement-treated sand and mortar using different cement types were sealed and cured at different temperatures. After casting into tin molds, the top surfaces of the specimens were immediately sealed with aluminum tape and cured at varying temperatures $\left(20^{\circ} \mathrm{C}\right.$ in a room and $40^{\circ} \mathrm{C}$ in a control chamber) for prescribed curing periods.

\subsection{Measurements}

\subsubsection{Unconfined compression test}

After the prescribed curing periods, the unconfined compression tests were conducted by reference to JIS A1216 in order to evaluate the compressive strengths of mortar and 
cement-treated sand. To reduce the effects of the unevenness of the surfaces, the upper surfaces of the mortar specimens were treated using a polishing machine; for the cementtreated sand, the upper surfaces were levelled using a metal straight ruler. The tests were performed at a constant loading rate of $0.1 \mathrm{~mm} / \mathrm{min}$ for both the mortar and cement-treated sand. The compressive strength at each age under each condition was the average value of the compressive strength of three specimens.

\subsubsection{Thermal analysis}

The amounts of chemically bound water and $\mathrm{Ca}(\mathrm{OH})_{2}(\mathrm{CH})$ were determined by thermal analysis (TG-DTA) to evaluate the degree of hydration and pozzolanic reaction. The amounts of chemically bound water and $\mathrm{CH}$ were calculated by removing the loss of $\mathrm{CaCO}_{3}$ decomposition and the loss on ignition of raw materials (cement, Toyoura silica sand).

\section{Results and discussion}

\subsection{Compressive strength}

First, to evaluate the effect of curing temperature on strength development of mortar and cement-treated sand using different cement types, the compressive strength ratios (between $40^{\circ} \mathrm{C}$ and $20^{\circ} \mathrm{C}$ ) of mortar and cement-treated sand are shown in Figs. 1 to 3. At early ages (from 1 to 3 days) the compressive strength ratios were higher than 1.0 for all cases; in particular, the ratios were much greater than 1.0 in the cement-treated sand. It implies that under $40^{\circ} \mathrm{C}$, the hydration of cement was accelerated, resulting in the increase in strength. However, for later ages, the ratios were approximately 1.0 or even smaller than 1.0 except for MPC. Overall, it can be seen that the compressive strength ratios decreased from 1 day to 91 days. Especially for the mortars using HPC and OPC, the compressive strength ratios at 28 and 91 days were lower than 1.0. This is because under high curing temperatures cement hydration occurs rapidly, which may create a barrier to ion diffusion, thus resulting in an inhomogeneity and increase in porosity, leading to a reduction in strength [16]. Conversely, for the case of MPC, the compressive strength ratios were larger than those in OPC and HPC for both mortars and cement-treated sand, and the ratios were even greater than 1.0 at 91 days. This may be related to MPC minerals that contain more $\mathrm{C}_{2} \mathrm{~S}$, which can reduce the negative effect of high curing temperatures.

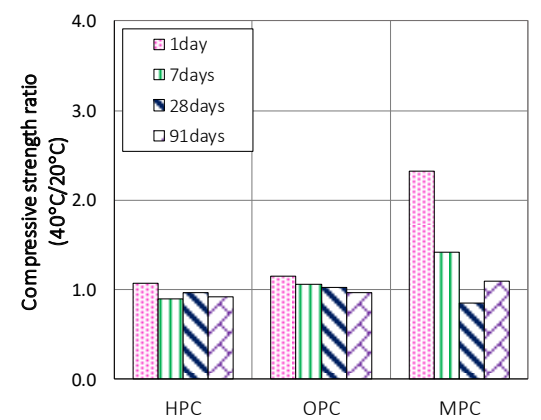

Fig. 1. Compressive strength ratio of different cement types for mortar (W/C $=50 \%, C=50 \%)$.

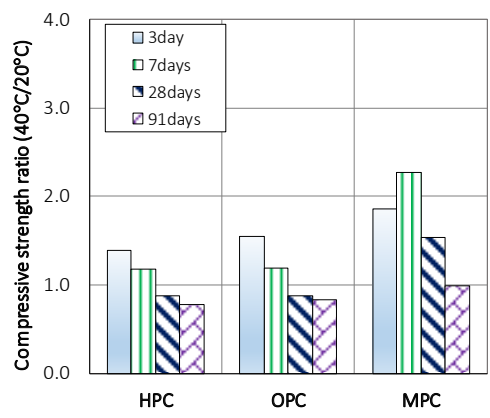

Fig. 2. Compressive strength ratio of different cement types for mortar $(\mathrm{W} / \mathrm{C}=100 \%$, $\mathrm{C}=25 \%$ ). 


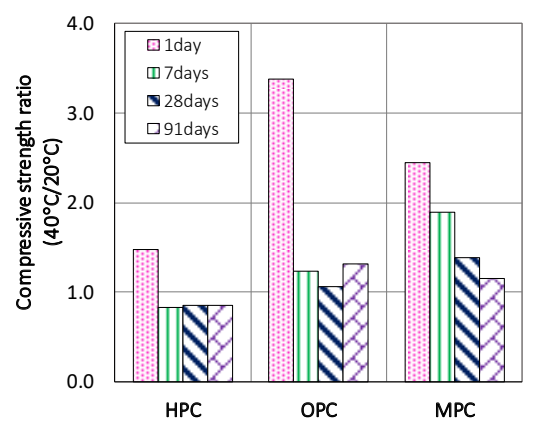

Fig. 3. Compressive strength ratio of different cement types for cement-treated sand (W/C $=100 \%$, $\mathrm{C}=8 \%$ ).

Second, to compare the effects of cement type and curing temperature on strength development of cement-treated sand and mortar, the relationship between the normalized compressive strength and cement content was established. Fig. 4 shows the relationship between the normalized compressive strength (ratios of the strength of other cases to the strength of $\mathrm{OPC}$ cured under $20^{\circ} \mathrm{C}$ ) and cement content at 7 days. From the figure, it can be seen that the effects of the cement type and curing temperature on the normalized compressive strength at 7 days were lower in the mortar with $\mathrm{W} / \mathrm{C}=50 \%$ compared with other cases. The normalized compressive strengths were around 1.0. However, for the case of the mortar with $\mathrm{W} / \mathrm{C}=100 \%$ and cement-treated sand, the normalized compressive strength of $\mathrm{HPC}$ and $\mathrm{OPC}$ under $40^{\circ} \mathrm{C}$ were higher than 1.2. Regarding the MPC, the normalized compressive strength was much lower than that of OPC and HPC; this is because the hydration speed of MPC may be lower than that in OPC and HPC at early ages. The normalized compressive strength increased with the decrease in the amount of cement (i.e from the case of the mortar with $\mathrm{W} / \mathrm{C}=50 \%$ to the case of cement-treated sand) for $\mathrm{HPC}$ and OPC.

Fig. 5 shows the normalized compressive strength at 91 days. The normalized compressive strengths in the case of the mortar with $\mathrm{W} / \mathrm{C}=50 \%$ were around 1.0 except the case of MPC under $40^{\circ} \mathrm{C}$. The normalized compressive strength increased with the decrease in the cement content for the specimen using HPC under $20^{\circ} \mathrm{C}$. For the cases of the mortar specimens using HPC and OPC under $40^{\circ} \mathrm{C}$, the normalized compressive strength values were lower than 1.0 (around 1.0 (at $\mathrm{W} / \mathrm{C}=50 \%$ ) and approximately 0.8 (at $\mathrm{W} / \mathrm{C}=$ $100 \%)$ ). This is because, under high curing temperatures, the crossover effect occurred, resulting in the decrease in the strength of the mortar. However, it can be observed that the normalized compressive strength was higher than 1.0 in the cement-treated sand for HPC, $\mathrm{OPC}$ and MPC under $40^{\circ} \mathrm{C}$. This increase can be explained by the pozzolanic reaction under high curing temperatures due to the high percentage of sand. For the case of MPC under $40^{\circ} \mathrm{C}$, the normalized compressive strength was greater than 1.0 for both the mortar and cement-treated sand because under high curing temperatures, the reaction of MPC may be accelerated at 91 days. 


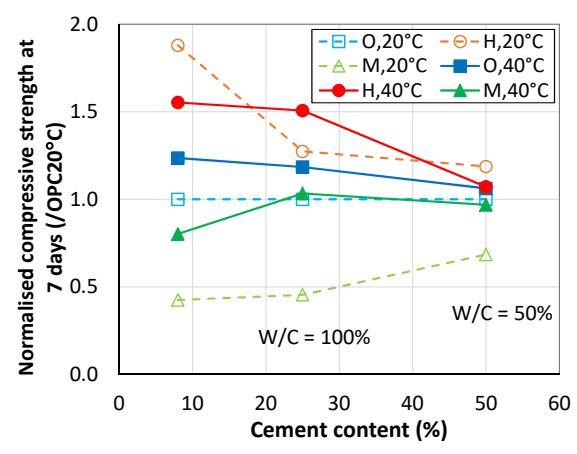

Fig. 4. Relationship between normalized compressive strength and cement content at 7 days.

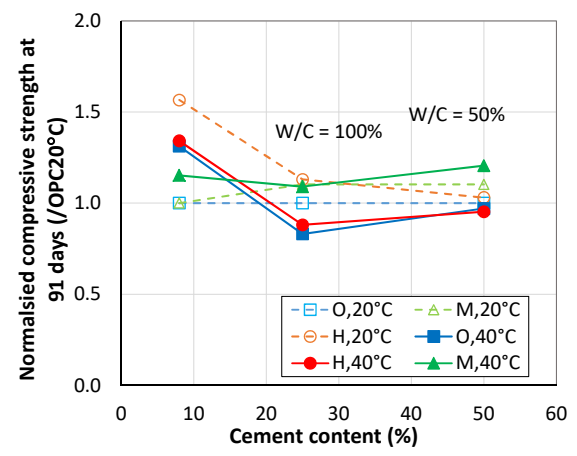

Fig. 5. Relationship between normalized compressive strength and cement content at 91 days.

\subsection{Amount of chemically bound water}

Due to the limitations of the experiment, the thermal analysis of MPC has not been conducted yet for mortar specimens. Fig. 6 shows the ratios of the amount of chemically bound water of other cases to the amount of chemically bound water of OPC with $\mathrm{W} / \mathrm{C}=$ $50 \%$ under $20^{\circ} \mathrm{C}$ in the mortars over time. At early ages, the ratios of all cases were higher than 1.0 except for the case of OPC with $\mathrm{W} / \mathrm{C}=100 \%$ under $20^{\circ} \mathrm{C}$; especially for the case of HPC, the ratios were approximately 1.4. These high ratios can explain the higher compressive strength observed in HPC and OPC under $40^{\circ} \mathrm{C}$ compared to the case of OPC under $20^{\circ} \mathrm{C}$. However, at the age of 91 days, the ratios fluctuated around 1.0 for all cases. It means that the amount of chemically bound water of other cases were almost same as in the case of OPC with $\mathrm{W} / \mathrm{C}=50 \%$ under $20^{\circ} \mathrm{C}$. This can partially explain why the normalized compressive strengths of mortar were approximately 1.0 for all cases.

Fig. 7 shows the ratio of the amount of chemically bound water of other cases to the amount of chemically bound water of OPC under $20^{\circ} \mathrm{C}$ in the cement-treated sand over time. At an early age ( 3 days), the ratios in the cases of HPC and OPC under $40^{\circ} \mathrm{C}$ were greater than 2.0. This higher amount of chemically bound water can explain the higher compressive strength as observed in the above discussion. However, for the case of MPC under $20^{\circ} \mathrm{C}$, the ratio was approximately 0.6 . This small ratio can demonstrate the lower strength found in the MPC under $20^{\circ} \mathrm{C}$. Generally, it can be observed that the ratios in cases of HPC and OPC under $40^{\circ} \mathrm{C}$ were greater than 1.0, but the ratio in the case of MPC under $20^{\circ} \mathrm{C}$ was almost smaller than 1.0. This indicates that the higher chemically bound water led to the higher compressive strength in the cases of HPC and OPC under $40^{\circ} \mathrm{C}$ compared to the case of OPC and MPC under $20^{\circ} \mathrm{C}$ in the cement-treated sand both short and long-term, as aforementioned. 


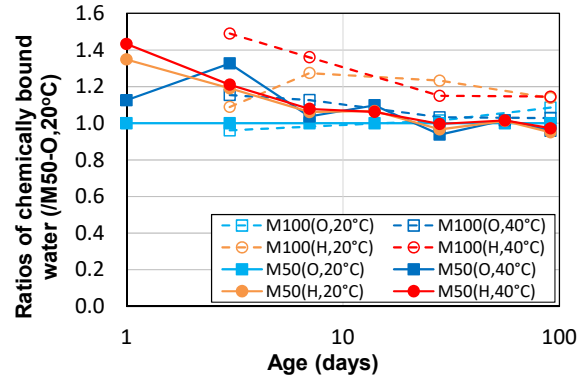

Fig. 6. Ratios of chemically bound water over time of mortars.

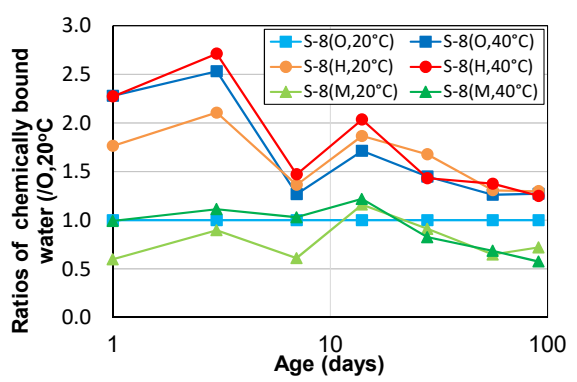

Fig. 7. Ratios of chemically bound water over time of cement-treated sand.

Furthermore, to investigate the pozzolanic reaction in the cement-treated sand, the relationship between the compressive strength and amounts of $\mathrm{CH}$ of the mortar with W/C $=100 \%$ and cement-treated sand were made for comparison (Figs. 8 and 9). It can be seen that there was a different trend. For the case of the mortar with W/C $=100 \%$, the compressive strength increased with the increase in the amount of $\mathrm{CH}$ (Fig. 8). However, for the case of the cement-treated sand (Fig. 9), the compressive strength increased when the amount of $\mathrm{CH}$ decreased under $40^{\circ} \mathrm{C}$ after 7 days in case of OPC and HPC. Thus, it can be inferred that the pozzolanic reaction occurred in the cement-treated sand under high curing temperatures caused by a large amount of sand, which had low pozzolanic reactivity as aforementioned.

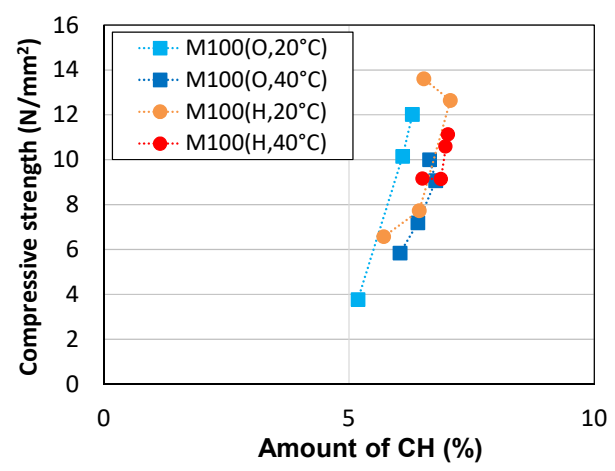

Fig. 8. Relationship between compressive strength and amount of $\mathrm{CH}$ of mortar $(\mathrm{W} / \mathrm{C}=$ $100 \%$ ).

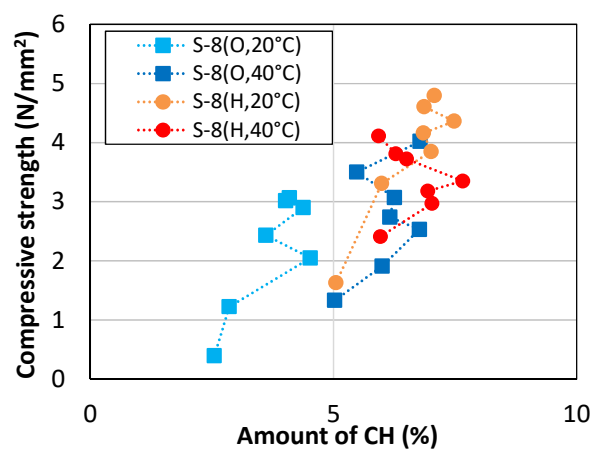

Fig. 9. Relationship between compressive strength and amount of $\mathrm{CH}$ of cement-treated sand.

\section{Conclusions}

Based on the results of the experiment, some conclusions can be drawn as follows.

1. The compressive strength of cement-treated increased rapidly at early ages due to the high curing temperature for all cement types in order of MPC, OPC, and HPC. The long-term compressive strength also increased for the cases of OPC and MPC under high curing temperatures.

2. The compressive strength of cement-treated sand using HPC was much higher than that using $\mathrm{OPC}$ and $\mathrm{MPC}$ under $20^{\circ} \mathrm{C}$ both short and long-term, due to the higher amount of chemically bound water. The compressive strength under $40^{\circ} \mathrm{C}$ was lower than that under $20^{\circ} \mathrm{C}$ for $\mathrm{HPC}$, but it was adverse in the case of OPC. Thus, it can be inferred that 
the strength increase caused by high curing temperature in the cement-treated sand was greatly affected by the cement type.

3. In addition, it was revealed that under high curing temperatures, the pozzolanic reaction was promoted in cases of cement-treated sand using HPC and OPC. This may be related to the high percentage of sand in the mixtures.

\section{References}

1. S. Horpibulsuk, N. Miura, T.S. Nagaraj, Géotechnique 53 (2003) 439-444.

2. G.A. Lorenzo, D.T. Bergado, J. Geotech. Geoenviron. Eng. 130 (2004) 1042-1050.

3. R. Bahar, M. Benazzoug, S. Kenai, Cem. Concr. Compos., 26 (7) (2004) 811-820.

4. M. Kitazume, M. Terashi, The Deep Mixing Method, CRC Press, London, (2013).

5. A. Enami, M. Yoshida, S. Hibino, M. Takahashi, K. Akitani, (1985). 1737-1740 (in Japanese).

6. Escalante-Garcia JI, Sharp JH, Cem Conc Res, 31 (2001) 695-702.

7. J.J. Brooks, A.F. Kaisi, ACI Mater J 87(5): (1990) 503-507.

8. J.K. Kim, Han SH, Park SK, Cem Conc Res, 32 (2002)1087-94.

9. J. Kim, Y. Moon, S. Eo, Cem Conc Res, 28 (1998), 1761-1773.

10. J. Kim, S. Han, Y. Song, Cem Conc Res, 32 (2002), 1087-1094.

11. K. Ezziane, A. Bougara, A. Kadri, H. Khelafi, E. Kadri, Cem. Concr. Compos, 29 (2007) 587-593.

12. R.J. Zhang, Y.T. Lu, T.S. Tan, K.K Phoon, A.M. Santoso, Journal of Geotechnical and Geoenvironmental Engineering, 140 (2014) 04014045.

13. D. Wang, R. Zentar, N.E. Abriak, Journal of Materials in Civil Engineering, 29 (5) (2016) 04016281.

14. L.S. Ho, K. Nakarai, Y. Ogawa, T. Sasaki, M. Morioka, Constr. Build. Mater, 134 (2017): 703-712.

15. L.S. Ho, K. Nakarai, Y. Ogawa, T. Sasaki, M. Morioka, Constr. Build. Mater, 166 (2018): 634-646.

16. T. Bakharev, J.G. Sanjayan, Y.B. Cheng, Cem Conc Res, 29 (1999) 1619-25. 